\title{
Review Article \\ Theragnostic Imaging Using Radiolabeled Antibodies and Tyrosine Kinase Inhibitors
}

\author{
Mitsuyoshi Yoshimoto, ${ }^{1}$ Hiroaki Kurihara, ${ }^{2}$ and Hirofumi Fujii ${ }^{1}$ \\ ${ }^{1}$ Division of Functional Imaging, National Cancer Center Hospital East, 6-5-1, Kashiwanoha, Kashiwa, Chiba 277-8577, Japan \\ ${ }^{2}$ Diagnostic Radiology, National Cancer Center Hospital, 5-1-1 Tsukiji, Chuo-ku, Tokyo 104-0045, Japan \\ Correspondence should be addressed to Mitsuyoshi Yoshimoto; miyoshim@ncc.go.jp
}

Received 23 June 2014; Revised 22 August 2014; Accepted 22 August 2014

Academic Editor: Kazuma Ogawa

Copyright (c) 2015 Mitsuyoshi Yoshimoto et al. This is an open access article distributed under the Creative Commons Attribution License, which permits unrestricted use, distribution, and reproduction in any medium, provided the original work is properly cited.

During the past decade, the efficacy of new molecular targeted drugs such as tyrosine kinase inhibitors (TKIs) and monoclonal antibodies has been proven worldwide, and molecular targeted therapies have become the mainstream in cancer therapy. However, clinical use of these new drugs presents unexpected adverse effects or poor therapeutic effects. Therefore, we require diagnostic tools to estimate the target molecule status in cancer tissues and predict therapeutic efficacy and adverse effects. Although immunohistochemical, polymerase chain reaction (PCR) and fluorescence in situ hybridization (FISH) analyses of biopsy samples are conventional and popular for this diagnostic purpose, molecular imaging modalities such as positron emission tomography (PET) and single photon emission computed tomography (SPECT) are also useful for noninvasive estimation of gene and protein expression and drug pharmacokinetics. In this review, we introduce new radiolabeled TKIs, antibodies, and their clinical application in molecular targeted therapy and discuss the issues of these imaging probes.

\section{Introduction}

New observations regarding carcinogenesis and signal transduction pathways that regulate tumor growth, differentiation, angiogenesis, invasion, and metastasis have led to the identification of potential therapeutic targets and have accelerated molecular targeted drug development. In particular, the success of imatinib in chronic myeloid leukemia (CML) patients has strongly promoted the development of smallmolecule tyrosine kinase inhibitors (TKIs). Since the United States Food and Drug Administration's approval of rituximab (Rituxan; anti-CD20 antibody) and imatinib (Gleevec; BcrAbl TKI), several anticancer drugs have been approved each year in the US, European Union, and Japan [1].

The antitumor mechanisms triggered by molecular targeted drugs differ from those of conventional chemotherapeutic agents. Therefore, the estimation of target molecule expression in entire tumor is required to predict therapeutic efficacy. Target molecule and target gene expressions can be evaluated using immunohistochemical, polymerase chain reaction (PCR) and fluorescence in situ hybridization (FISH) analyses of biopsy samples. However, biopsy samples contain tissues from limited regions only, whereas tumor tissue is heterogeneous. Thus, it is possible that the expression observed in biopsy samples is not representative of that in entire tumor $[2,3]$. This can lead to a misunderstanding with respect to tumor characterization. Moreover, expression levels of key molecules and gene mutations require modulation during treatment. The consequent repetitive biopsies are invasive and represent a significant burden on patients.

Molecular imaging modalities such as positron emission tomography (PET) and single photon emission computed tomography (SPECT) are suitable for noninvasive estimation of gene and protein expressions and drug pharmacokinetics $[4,5]$. Molecular imaging also enables detection of changes in gene and protein expressions in response to treatment in the entire tumor and could overcome the issues associated with biopsy. Therefore, PET and SPECT are the best tools in treatment strategies that combine therapeutics with diagnostics, also known as "theragnostics."

Theragnostic imaging by using radiolabeled molecular targeted drugs provides new important insights into drug 
<smiles>CCCC(Oc1cc2ncnc(Nc3ccc(F)c(Cl)c3)c2cc1OCCCN1CCOCC1)C(F)(F)F</smiles>

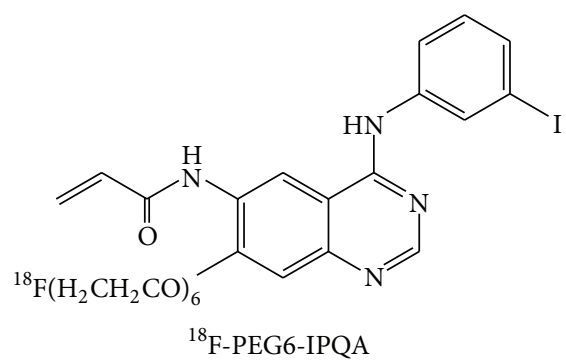<smiles>CN(C)C/C=C/C(=O)Nc1cc2c(Nc3cc(Cl)c(Cl)cc3F)ncnc2cc1C(=O)OCCO</smiles><smiles>CCCC(=O)c1cc2ncnc(Nc3cc(Cl)c(Cl)cc3F)c2cc1NC(=O)/C=C/CN(C)CCCCCCC(F)F</smiles><smiles>CN(C)C/C=C/C(=O)Nc1cc2c(Nc3cccc(Br)c3)ncnc2cc1C(=O)CCO</smiles><smiles>CCOc1cc2ncnc(Oc3cccc([131I])c3)c2cc1OCC</smiles>

FIGURE 1: Chemical structures of the EGFR-TK imaging probes.

development and cancer treatment. For instance, theragnostic imaging reveals pharmacokinetics of drugs in individual patients. This allows stratification of the patients who would benefit from the drugs and identification of modified status of target molecules (expression levels and mutation status). Moreover, understanding of the pharmacokinetics is helpful to select candidate drugs in the process of drug development, resulting in reduction of development cost.

\section{Development of Imaging Agents for Epidermal Growth Factor Receptor-Tyrosine Kinase (Figure 1)}

The small molecule epidermal growth factor receptor (EGFR)-TKIs gefitinib and erlotinib have been approved for the treatment of non-small-cell lung cancer (NSCLC) and have exhibited dramatic antitumor activities. These therapeutic agents have been found to be effective primarily in patients with mutant EGFR-TK [6-8]. However, gefitinib treatment has also led to serious side effects such as interstitial lung disease [9]. In addition, the gefitinib treatment will result in acquisition of resistance usually within a year, half of whose mechanism is secondary T790M mutation of the EGFR gene [10]. These clinical findings demonstrate the need to detect mutation status of the target molecule.

The simplest strategy for estimation of gefitinib sensitivity and mutation status is the use of radiolabeled gefitinib (Figure 1) [11, 12]. However, a discrepancy in specificity of radiolabeled gefitinib exists between ${ }^{18} \mathrm{~F}$-gefitinib and ${ }^{11} \mathrm{C}$ gefitinib. Su et al. reported that ${ }^{18} \mathrm{~F}$-gefitinib uptake in vitro and in vivo did not correlate with EGFR expression because of nonspecific binding caused by its high lipophilicity [11]. An in vitro uptake study indicated that high and specific ${ }^{18} \mathrm{~F}$ gefitinib uptake was observed only in $\mathrm{H} 3255$ with mutant EGFR, but not in U87-EGFR. Unlike ${ }^{18} \mathrm{~F}$-gefitinib, specific ${ }^{11} \mathrm{C}$-gefitinib uptake was observed in mice bearing murine fibrosarcoma (NFSa) [12]. However, a biodistribution study has shown that ${ }^{11} \mathrm{C}$-gefitinib uptake was low in A431 cells which exhibit high EGFR expression. Thus, radiolabeled gefitinib may not estimate EGFR expression or mutation status.

A reduction in lipophilicity might be a simple solution to overcome the nonspecific binding of an imaging probe. 
However, a certain level of imaging probe lipophilicity is essential for passage through the cell membrane and binding to the ATP binding pocket in the TK domain of the target molecule. A recent PET study indicated the failure of EGFR-expressing U-87MG cells to take up polyethylene glycol(PEG)-ylated anilinoquinazoline derivatives $\left({ }^{11} \mathrm{C}\right.$ $1,{ }^{18} \mathrm{~F}-2$, and $\left.{ }^{124} \mathrm{I}-3\right)$ [13]. However, PET using 4-[(3-iodophenyl $)$ amino $]-7-\left(2-\left[2-\left\{2-\left(2-\left[2-\left\{2-\left({ }^{18} \mathrm{~F}\right.\right.\right.\right.\right.\right.\right.$-fluoroethoxy)ethoxy\}-ethoxy]-ethoxy)-ethoxy\}-ethoxy]-quinazoline-6-ylacrylamide) $\left({ }^{18} \mathrm{~F}\right.$-PEG6- IPQA) could delineate tumors with high EGFR expression [14]. These inhibitors are irreversible (Figure 1). Although the affinities $\left(\mathrm{K}_{\mathrm{D}}\right)$ of these compounds for EGFR-TK are not clear, an understanding of the relationships between lipophilicity, affinity, and the binding mode (reversible or irreversible) might lead to a breakthrough in the development of TK imaging probes.

\section{Estimation of the Mutation Status Using EGFR-TK Imaging Probes}

Monitoring of EGFR-TKI sensitivity and mutation status of the target molecule is of particular interest to the field of molecular imaging. We previously reported a correlation between the tumor uptake of 4-(3- ${ }^{125} \mathrm{I}$-iodo-phenoxy)-6,7diethoxy-quinazoline ( ${ }^{125}$ I-PHY, Figure 1$)$ and gefitinib sensitivity [15]. However, differences in tumor uptake were due partly to differences in EGFR expression and partly to nonspecific binding. Unfortunately, ${ }^{125} \mathrm{I}$-PHY could not estimate differences in mutation statuses. Yeh et al. attempted to detect a gefitinib-sensitive mutation (L858R) using ${ }^{18}$ F-PEG6-IPQA which selectively and irreversibly binds to mutant EGFRTK (L858R) [14]. An in silico docking study revealed that the acrylamide moiety of F-PEG6-IPQA can form a covalent bond with Cys773 in the active conformation of L858R mutant kinase domain. A PET study involving ${ }^{18}$ F-PEG6IPQA demonstrated high uptake in $\mathrm{H} 3255$ cells harboring the L858R mutation.

Memon et al. reported high and sustained ${ }^{11} \mathrm{C}$-erlotinib uptake in HCC827 cells harboring a delE746-750 mutations as compared with A549 and NCI358 cells [16]. This difference was caused by different affinities of erlotinib to EGFRTKs [17]. A recent clinical study has supported these basic research findings. A PET study involving ${ }^{11} \mathrm{C}$-erlotinib was conducted in patients with wild-type (WT) and Exon19 deletion mutation. Although patients harboring the common L858R mutation were not included, the uptake of ${ }^{11} \mathrm{C}$ erlotinib was higher in tumors with the deletion mutation than those with WT [18]. Moreover, these ${ }^{11} \mathrm{C}$-erlotinib studies suggest that reversible inhibitors are efficient imaging probes for estimating the mutation status based on differences in binding affinity.

Unfortunately, this study has some limitation. Only a small number of patients (5 with and 5 without a mutation) were involved. Patients with other mutation (L858R and L858R/T790 M) were not included. Further investigation is needed to demonstrate that ${ }^{11} \mathrm{C}$-erlotinib PET is as efficient as the conventional mutation test using the biopsied samples.

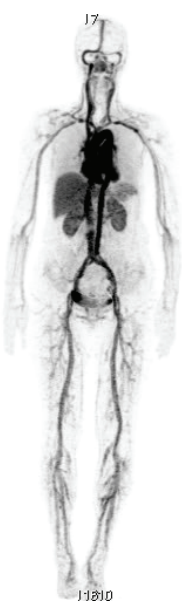

$6 \mathrm{~h}$

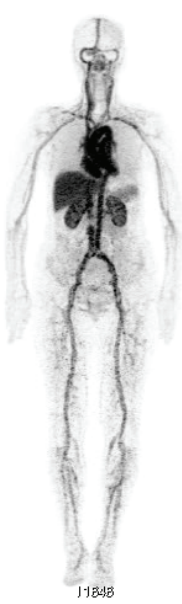

$24 \mathrm{~h}$

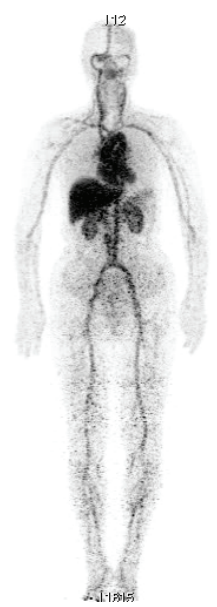

$48 \mathrm{~h}$
Figure 2: Whole-body ${ }^{64} \mathrm{Cu}$-DOTA-trastuzumab PET images at 6, 24 , and $48 \mathrm{~h}$ after injection.

\section{Human Epidermal Growth Factor Receptor 2 (HER2) Imaging}

Anti-HER2 therapy with trastuzumab, a monoclonal antibody, is now well established in HER2-positive breast cancer patients $[19,20]$. Although HER2 expression is estimated using immunohistochemical or FISH analyses of biopsy samples, core needle biopsy is not possible for some lesions [21]. In addition, HER2 status can change during disease progression and over the course of the treatment $[22,23]$.

There have been many reports of the use of radiolabeled trastuzumab in animal and human studies (Figure 2) [24-28]. McLarty et al. reported that the tumor uptake of ${ }^{111}$ In-DTPAtrastuzumab, after correcting for nonspecific IgG accumulation and circulating radioactivity, exhibited strong nonlinear associations with the HER2 density in a mouse model of breast cancer [29]. PET with ${ }^{89} \mathrm{Zr}$-trastuzumab could detect downregulation of HER2 expression in response to afatinib treatment in a gastric cancer xenograft model [30]. Moreover, the first-in-human study of ${ }^{89} \mathrm{Zr}$-trastuzumab PET resulted in tumor visualization and quantitative tracer uptake in HER2positive tumors [24].

A long duration of antibody circulation leads to a high background signal, and therefore a long period of time is needed to decrease the radioactivity in the blood and acquire specific images of the target tissues. Although metal radionuclides with long half-lives such as ${ }^{111} \mathrm{In}$ and ${ }^{89} \mathrm{Zr}$ $(67.9 \mathrm{~h}$ and $78.4 \mathrm{~h}$, resp.) are appropriate for in vivo imaging with radiolabeled antibodies, the use of these radionuclides results in high levels of radiation exposure. Tamura et al. reported that ${ }^{64} \mathrm{Cu}$-DOTA-trastuzumab could delineate HER2-positive lesions including brain metastases in breast carcinoma patients; further, the use of ${ }^{64} \mathrm{Cu}$ (half-life $=12.7 \mathrm{~h}$ ) could reduce the radiation exposure to $4.5 \mathrm{mSv}$ versus the $18 \mathrm{mSv}$ from ${ }^{89} \mathrm{Z}$-trastuzumab [24, 28]. This effective dose is similar to that of ${ }^{18}$ F-FDG $(0.019 \mathrm{mSv} / \mathrm{MBq})$ [31]. 


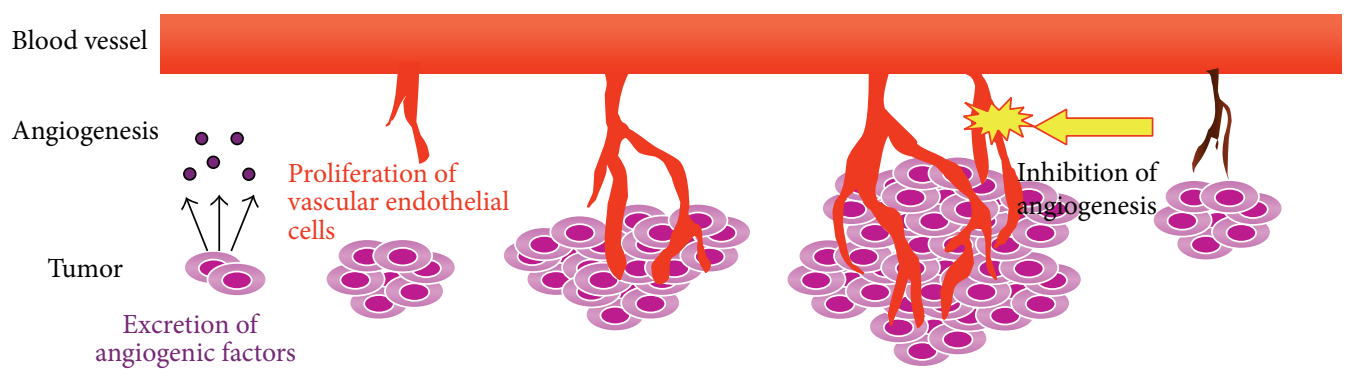

FIGURE 3: Depiction of tumor angiogenesis. Angiogenesis is an important tumor growth factor. Vascular endothelial cell proliferation is essential for the development of new blood vessels.

\section{Vascular Endothelial Growth Factor (VEGF) Imaging}

Antiangiogenic therapy is a cancer treatment strategy $[32,33]$. Angiogenesis consists of various processes such as the secretion of angiogenic factors and the proliferation of vascular endothelial cells (ECs; Figure 3). Bevacizumab is a monoclonal anti-VEGF antibody that inhibits VEGF-stimulated EC proliferation [34, 35]. Vandetanib, a VEGFR-TK inhibitor, directly inhibits EC proliferation because VEGF expression is upregulated within tumor tissues [36, 37]. Antiangiogenic drugs directly or indirectly inhibit EC proliferation followed by tumor suppression. Therefore, to decide the therapeutic plan using antiangiogenic drugs, we should estimate the expression level of the target molecule, but not the biological activity of tumor cells.

Molecular imaging could be a powerful tool for estimating the VEGF content within tumor tissues. Enzyme-linked immunosorbent assays of tissue samples measure not only extracellular but also intracellular VEGF content. The first clinical study of ${ }^{89} \mathrm{Zr}$-bevacizumab PET conducted in breast cancer patients indicated a correlation between the maximum standard uptake values of the tracer and VEGF-A expression in the tumors [38]. Chang et al. reported that ${ }^{64} \mathrm{Cu}-\mathrm{NOTA}-$ bevacizumab could be used to evaluate a decrease in the expression of VEGF caused by everolimus, a mammalian target of rapamycin inhibitor [39].

\section{Other Kinase Imaging with Radiolabeled Small Molecules}

New kinase inhibitors have been labeled with ${ }^{11} \mathrm{C}$ or ${ }^{18} \mathrm{~F}$; these include ${ }^{11} \mathrm{C}$-vandetanib, ${ }^{18} \mathrm{~F}$-SKI696 (an analogue of imatinib), and ${ }^{18}$ F-sunitinib [40-46]. However, their chemical structures must be modified for compatibility with the imaging probes. The biodistribution of ${ }^{11} \mathrm{C}$-sorafenib indicated high radioactivity in the liver and slow blood clearance [46]. The tumor uptake of ${ }^{11} \mathrm{C}$-sorafenib was lower than its radioactivity level in blood. In view of selectivity, we could not deduce which kinases contribute to tumor uptake because sorafenib is a multikinase inhibitor. The properties of the oral drugs that are high bioavailability and high blood concentration may be unfavorable for imaging probes. Therefore, optimization of chemical structures would be required for use of kinase inhibitors for imaging probes. The use of radiolabeled kinase inhibitors may be limited to the purpose of estimating pharmacokinetics and drug concentrations.

\section{Conclusion}

Targeted therapy is becoming the mainstream in the field of cancer therapy, and the development of new targeted drugs is increasing. However, the therapeutic effects of the agents remain limited, and patients who benefit from targeted therapy represent a fraction of all patients. Molecular imaging plays two roles in targeted therapy. The first role is the estimation of features of the target molecules such as the expression level and mutation status, thus allowing patient stratification. The second role is the elucidation of pharmacokinetics and measurement of drug concentrations in the tissues. Drug radiolabeling is sufficient for the latter purpose, whereas the former requires imaging probes for the acquisition of informative images. We should readily try to optimize the chemical structures of kinase inhibitors for use as imaging probes instead of antibodies. We believe that advances in imaging probes will contribute to our understanding of pharmacokinetics/pharmacodynamics, drug development, and therapy planning.

\section{Conflict of Interests}

The authors declare that there is no conflict of interests regarding the publication of this paper.

\section{References}

[1] G. Walsh, "Biopharmaceutical benchmarks," Nature Biotechnology, vol. 28, no. 9, pp. 917-924, 2010.

[2] A. P. Dei Tos and I. Ellis, "Assessing epidermal growth factor receptor expression in tumours: what is the value of current test methods?" European Journal of Cancer, vol. 41, no. 10, pp. 13831392, 2005.

[3] A. Crockford, M. Jamal-Hanjani, J. Hicks, and C. Swanton, "Implications of intratumour heterogeneity for treatment stratification," The Journal of Pathology, vol. 232, pp. 264-273, 2014. 
[4] E. G. E. de Vries, T. H. O. Munnink, M. A. T. M. van Vugt, and W. B. Nagengast, "Toward molecular imaging-driven drug development in oncology," Cancer Discovery, vol. 1, no. 1, pp. 25-28, 2011.

[5] M. L. Thakur, "Genomic biomarkers for molecular imaging: predicting the future," Seminars in Nuclear Medicine, vol. 39, no. 4, pp. 236-246, 2009.

[6] T. J. Lynch, D. W. Bell, R. Sordella et al., "Activating mutations in the epidermal growth factor receptor underlying responsiveness of non-small-cell lung cancer to gefitinib," The New England Journal of Medicine, vol. 350, no. 21, pp. 2129-2139, 2004.

[7] H. Linardou, I. J. Dahabreh, D. Bafaloukos, P. Kosmidis, and S. Murray, "Somatic EGFR mutations and efficacy of tyrosine kinase inhibitors in NSCLC," Nature Reviews Clinical Oncology, vol. 6, no. 6, pp. 352-366, 2009.

[8] J. G. Paez, P. A. Jänne, J. C. Lee et al., "EGFR mutations in lung, cancer: correlation with clinical response to gefitinib therapy," Science, vol. 304, no. 5676, pp. 1497-1500, 2004.

[9] A. Inoue, Y. Saijo, M. Maemondo et al., "Severe acute interstitial pneumonia and gefitinib," The Lancet, vol. 361, no. 9352, pp. 137139, 2003.

[10] S. Kobayashi, T. J. Boggon, T. Dayaram et al., "EGFR mutation and resistance of non-small-cell lung cancer to gefitinib," The New England Journal of Medicine, vol. 352, no. 8, pp. 786-792, 2005.

[11] H. Su, Y. Seimbille, G. Z. Ferl et al., "Evaluation of $\left[{ }^{18} \mathrm{~F}\right]$ gefitinib as a molecular imaging probe for the assessment of the epidermal growth factor receptor status in malignant tumors," European Journal of Nuclear Medicine and Molecular Imaging, vol. 35, no. 6, pp. 1089-1099, 2008.

[12] M.-R. Zhang, K. Kumata, A. Hatori et al., " $\left.{ }^{11} \mathrm{C}\right]$ Gefitinib $\left(\left[{ }^{11} \mathrm{C}\right]\right.$ Iressa): radiosynthesis, in vitro uptake, and in vivo imaging of intact murine fibrosarcoma," Molecular Imaging and Biology, vol. 12, no. 2, pp. 181-191, 2010.

[13] M. A. Pantaleo, E. Mishani, C. Nanni et al., "Evaluation of modified PEG-anilinoquinazoline derivatives as potential agents for EGFR imaging in cancer by small animal PET," Molecular Imaging and Biology, vol. 12, no. 6, pp. 616-625, 2010.

[14] H. H. Yeh, K. Ogawa, J. Balatoni et al., "Molecular imaging of active mutant L858R EGF receptor (EGFR) kinase-expressing nonsmall cell lung carcinomas using PET/CT," Proceedings of the National Academy of Sciences of the United States of America, vol. 108, no. 4, pp. 1603-1608, 2011.

[15] M. Yoshimoto, M. Hirata, Y. Kanai et al., "Monitoring of gefitinib sensitivity with radioiodinated PHY based on EGFR expression," Biological and Pharmaceutical Bulletin, vol. 37, pp. 355-360, 2014.

[16] A. A. Memon, S. Jakobsen, F. Dagnaes-Hansen, B. S. Sorensen, S. Keiding, and E. Nexo, "Positron emission tomography (PET) imaging with $\left[{ }^{11} \mathrm{C}\right]$-labeled erlotinib: a micro-PET study on mice with lung tumor xenografts," Cancer Research, vol. 69, no. 3, pp. 873-878, 2009.

[17] K. D. Carey, A. J. Garton, M. S. Romero et al., "Kinetic analysis of epidermal growth factor receptor somatic mutant proteins shows increased sensitivity to the epidermal growth factor receptor tyrosine kinase inhibitor, erlotinib," Cancer Research, vol. 66, no. 16, pp. 8163-8171, 2006.

[18] I. Bahce, E. F. Smit, M. Lubberink et al., "Development of $\left[{ }^{11} \mathrm{C}\right]$ erlotinib positron emission tomography for in vivo evaluation of EGF receptor mutational status," Clinical Cancer Research, vol. 19, no. 1, pp. 183-193, 2013.
[19] I. Kümler, M. K. Tuxen, and D. L. Nielsen, "A systematic review of dual targeting in HER2-positive breast cancer," Cancer Treatment Reviews, vol. 40, no. 2, pp. 259-270, 2014.

[20] D. J. Slamon, B. Leyland-Jones, S. Shak et al., "Use of chemotherapy plus a monoclonal antibody against HER2 for metastatic breast cancer that overexpresses HER2," The New England Journal of Medicine, vol. 344, no. 11, pp. 783-792, 2001.

[21] A. Lebeau, A. Turzynski, S. Braun et al., "Reliability of human epidermal growth factor receptor 2 immunohistochemistry in breast core needle biopsies," Journal of Clinical Oncology, vol. 28, no. 20, pp. 3264-3270, 2010.

[22] C. Xiao, Y. Gong, E. Y. Han, A. M. Gonzalez-Angulo, and N. Sneige, "Stability of HER2-positive status in breast carcinoma: a comparison between primary and paired metastatic tumors with regard to the possible impact of intervening trastuzumab treatment," Annals of Oncology, vol. 22, no. 7, pp. 1547-1553, 2011.

[23] E. A. Mittendorf, Y. Wu, M. Scaltriti et al., "Loss of HER2 amplification following trastuzumab-based neoadjuvant systemic therapy and survival outcomes," Clinical Cancer Research, vol. 15, no. 23, pp. 7381-7388, 2009.

[24] E. C. Dijkers, T. H. Oude Munnink, J. G. Kosterink et al., "Biodistribution of ${ }^{89} \mathrm{Zr}$-trastuzumab and PET imaging of HER2-positive lesions in patients with metastatic breast cancer," Clinical Pharmacology and Therapeutics, vol. 87, no. 5, pp. 586592, 2010.

[25] M. N. Lub-de Hooge, J. G. W. Kosterink, P. J. Perik et al., "Preclinical characterisation of ${ }^{111}$ In-DTPA-trastuzumab," British Journal of Pharmacology, vol. 143, no. 1, pp. 99-106, 2004.

[26] T. H. Oude Munnink, M. A. D. Korte, W. B. Nagengast et al., “ ${ }^{89} \mathrm{Zr}$-trastuzumab PET visualises HER2 downregulation by the HSP90 inhibitor NVP-AUY922 in a human tumour xenograft," European Journal of Cancer, vol. 46, no. 3, pp. 678-684, 2010.

[27] P. J. Perik, M. N. Lub-De Hooge, J. A. Gietema et al., "Indium111-labeled trastuzumab scintigraphy in patients with human epidermal growth factor receptor 2-positive metastatic breast cancer," Journal of Clinical Oncology, vol. 24, no. 15, pp. 2276$2282,2006$.

[28] K. Tamura, H. Kurihara, K. Yonemori et al., "64 Cu-DOTAtrastuzumab PET imaging in patients with HER2-positive breast cancer," Journal of Nuclear Medicine, vol. 54, pp. 1869$1875,2013$.

[29] K. McLarty, B. Cornelissen, D. A. Scollard, S. J. Done, K. Chun, and R. M. Reilly, "Associations between the uptake of ${ }^{111}$ In-DTPA-trastuzumab, HER2 density and response to trastuzumab (Herceptin) in athymic mice bearing subcutaneous human tumour xenografts," European Journal of Nuclear Medicine and Molecular Imaging, vol. 36, no. 1, pp. 81-93, 2009.

[30] Y. Y. Janjigian, N. Viola-Villegas, J. P. Holland et al., "Monitoring afatinib treatment in HER2-positive gastric cancer with ${ }^{18} \mathrm{~F}$ FDG and ${ }^{89}$ Zr-trastuzumab PET," Journal of Nuclear Medicine, vol. 54, no. 6, pp. 936-943, 2013.

[31] D. Delbeke, R. E. Coleman, M. J. Guiberteau et al., "Procedure guideline for tumor imaging with ${ }^{18}$ F-FDG PET/CT 1.0," Journal of Nuclear Medicine, vol. 47, no. 5, pp. 885-895, 2006.

[32] N. Ferrara and T. Davis-Smyth, "The biology of vascular endothelial growth factor," Endocrine Reviews, vol. 18, no. 1, pp. 4-25, 1997.

[33] J. Folkman, "Tumor angiogenesis: therapeutic implications," The New England Journal of Medicine, vol. 285, no. 21, pp. 1182$1186,1971$.

[34] L. G. Presta, H. Chen, S. J. O'Connor et al., "Humanization of an anti-vascular endothelial growth factor monoclonal antibody 
for the therapy of solid tumors and other disorders," Cancer Research, vol. 57, no. 20, pp. 4593-4599, 1997.

[35] C. G. Willett, Y. Boucher, E. di Tomaso et al., "Direct evidence that the VEGF-specific antibody bevacizumab has antivascular effects in human rectal cancer," Nature Medicine, vol.10, pp. 145147, 2004.

[36] F. Ciardiello, R. Bianco, R. Caputo et al., "Antitumor Activity of ZD6474, a vascular endothelial growth factor receptor tyrosine kinase inhibitor, in human cancer cells with acquired resistance to antiepidermal growth factor receptor therapy," Clinical Cancer Research, vol. 10, no. 2, pp. 784-793, 2004.

[37] S. R. Wedge, D. J. Ogilvie, M. Dukes et al., "ZD6474 inhibits vascular endothelial growth factor signaling, angiogenesis, and tumor growth following oral administration," Cancer Research, vol. 62, no. 16, pp. 4645-4655, 2002.

[38] S. B. M. Gaykema, A. H. Brouwers, M. N. L.-D. Hooge et al., "89 Zr-bevacizumab PET imaging in primary breast cancer," Journal of Nuclear Medicine, vol. 54, no. 7, pp. 1014-1018, 2013.

[39] A. J. Chang, R. Sohn, Z. H. Lu, J. M. Arbeit, and S. E. Lapi, "Detection of rapalog-mediated therapeutic response in renal cancer xenografts using ${ }^{64} \mathrm{Cu}$-bevacizumab immunoPET," PLoS ONE, vol. 8, no. 3, Article ID e58949, 2013.

[40] T. Kniess, R. Bergmann, M. Kuchar, J. Steinbach, and F. Wuest, "Synthesis and radiopharmacological investigation of 3$\left[4^{\prime}-\left[{ }^{18} \mathrm{~F}\right]\right.$ fluorobenzylidene] indolin-2-one as possible tyrosine kinase inhibitor," Bioorganic and Medicinal Chemistry, vol. 17, no. 22, pp. 7732-7742, 2009.

[41] Z. Peng, D. S. Maxwell, D. Sun et al., "Imatinib analogs as potential agents for PET imaging of Bcr-Abl and c-KIT expression at a kinase level," Bioorganic \& Medicinal Chemistry, vol. 22, pp. 623-632, 2014.

[42] M. Gao, C. M. Lola, M. Wang, K. D. Miller, G. W. Sledge, and Q.-H. Zheng, "Radiosynthesis of $\left[{ }^{11} \mathrm{C}\right]$ Vandetanib and $\left[{ }^{11} \mathrm{C}\right]$ chloro- Vandetanib as new potential PET agents for imaging of VEGFR in cancer," Bioorganic and Medicinal Chemistry Letters, vol. 21, no. 11, pp. 3222-3226, 2011.

[43] J.-Q. Wang, K. D. Miller, G. W. Sledge, and Q.-H. Zheng, "Synthesis of $\left[{ }^{18} \mathrm{~F}\right] \mathrm{SU} 11248$, a new potential PET tracer for imaging cancer tyrosine kinase," Bioorganic and Medicinal Chemistry Letters, vol. 15, no. 19, pp. 4380-4384, 2005.

[44] E. Samén, J.-O. Thorell, L. Lu, T. Tegnebratt, L. Holmgren, and S. Stone-Elander, "Synthesis and preclinical evaluation of $\left[{ }^{11} \mathrm{C}\right] \mathrm{PAQ}$ as a PET imaging tracer for VEGFR-2," European Journal of Nuclear Medicine and Molecular Imaging, vol. 36, no. 8, pp. 1283-1295, 2009.

[45] A. P. Glekas, N. K. Pillarsetty, B. Punzalan, N. Khan, P. Smith-Jones, and S. M. Larson, "In vivo imaging of Bcr-Abl overexpressing tumors with a radiolabeled imatinib analog as an imaging surrogate for imatinib," Journal of Nuclear Medicine, vol. 52, no. 8, pp. 1301-1307, 2011.

[46] A. J. Poot, B. van der Wildt, M. Stigter-van Walsum et al., "[ $\left[{ }^{11} \mathrm{C}\right]$ Sorafenib: radiosynthesis and preclinical evaluation in tumor-bearing mice of a new TKI-PET tracer," Nuclear Medicine and Biology, vol. 40, no. 4, pp. 488-497, 2013. 


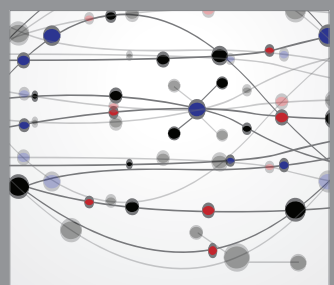

The Scientific World Journal
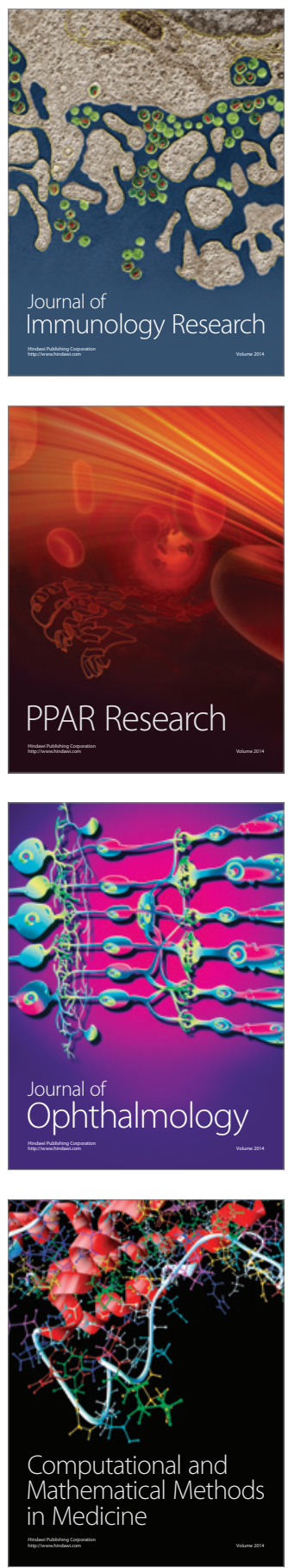

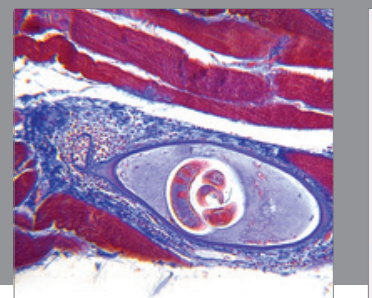

Gastroenterology

Research and Practice
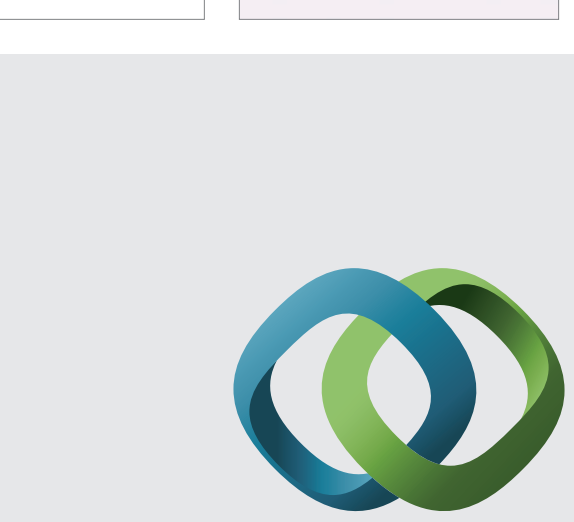

\section{Hindawi}

Submit your manuscripts at

http://www.hindawi.com
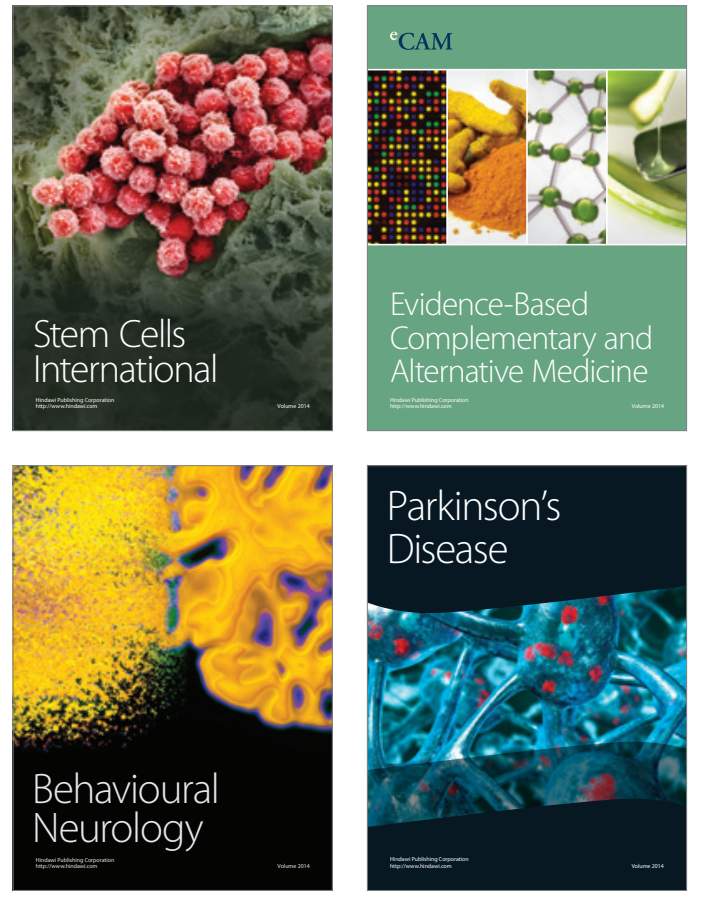
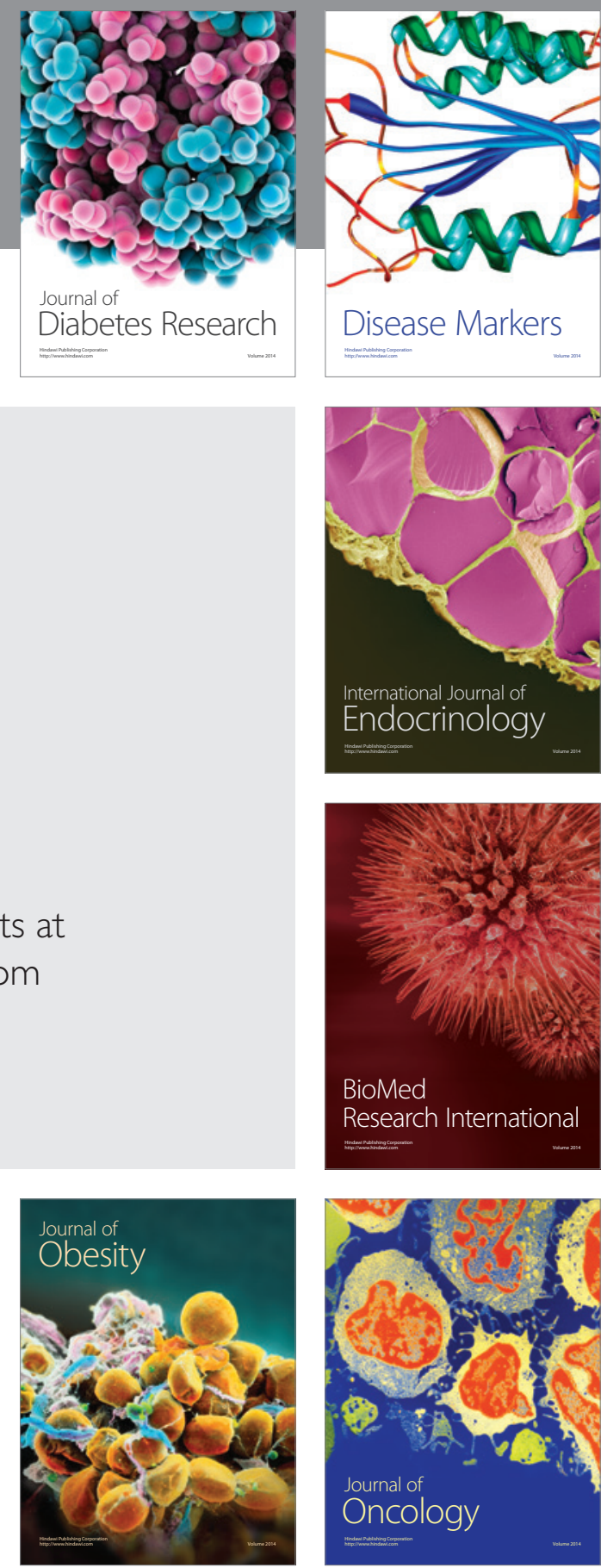

Disease Markers
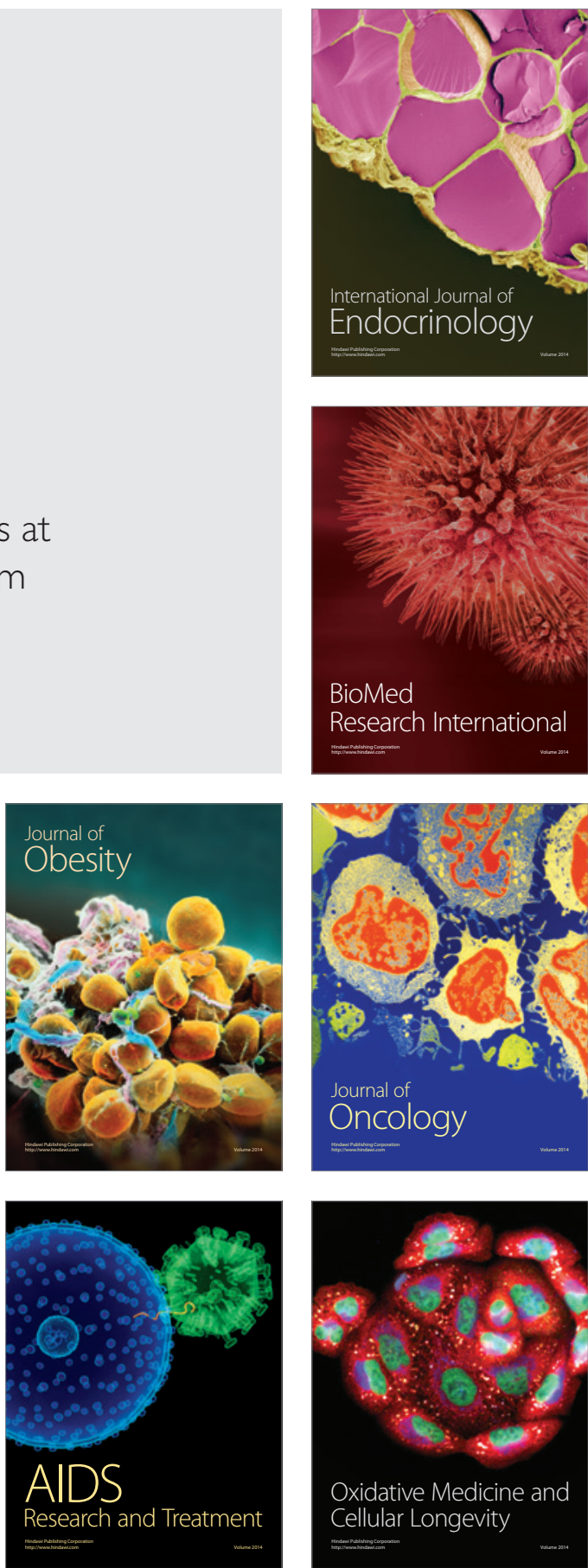